\title{
Family Involvement in Child Education and the Family-School Relationship in Romania
}

\author{
Costică $\operatorname{Lupu}^{1 *}$
}

\section{ABSTRACT}

The two fields, science and research, are in a relationship of mutual conditioning, meaning that there can be no science without research and no research can be conducted outside the normative framework of science. In the current context, these links appear to be more necessary than ever. Indeed, the social mission of the school increasingly surpasses the mere achievement of the pedagogical objectives from the school curriculum, given also the fact that many parents are too concerned with family, social or professional problems in order to be able to attend to their child's progress or the consistency between the education that the child receives and the education received by the child in the family and at school. To this end, we conducted an experimental research aiming to optimize the study of concrete possibilities for improving the school-family communication and the consequences entailed by this optimization. The main purpose of this questionnaire was to identify the students' opinion about the school's involvement of the family in their education and the consequences of a more aggressive involvement of parents in their children's education. The research subjects are students in the 12th grade, the Profile Services, the domain of Tourism and food, and their parents. The team of this class consists of 92 students, 44 girls and 48 boys from different backgrounds, with socially and financially vulnerable, 36 of them from urban areas and the remaining 56 families from rural areas. Based on the fact that during the school year, from the first meeting with the parents and until the present moment I have managed to build and develop a partnership relationship between the parents of the students in my class and the school, represented by the unit management, teachers and myself as head teacher of the respective class, I believe that the strategies (methods and techniques) used were effective and gave the expected result. This relationship should be further maintained and developed in order to achieve the results that we want in our work as educators. The conclusion we should draw is that cooperation between school and family means an agreement where each partner should respond to the other's needs and intentions. In order for

\footnotetext{
${ }^{1}$ Faculty of Sciences, Department of Mathematics-Informatics and Education Sciences "Vasile Alecsandri" University of Bacău, Str. Mărășești 157, România *Responding Author

Received: February 19, 2017; Revision Received: March 19, 2017; Accepted: March 23, 2017

(C) 2017 Lupu C; licensee IJIP. This is an Open Access Research distributed under the terms of the Creative Commons Attribution License (www.creativecommons.org/licenses/by/2.0), which permits unrestricted use, distribution, and reproduction in any Medium, provided the original work is properly cited.
} 
Family Involvement in Child Education and the Family-School Relationship in Romania

this to be possible, parents should contact the school not only when they are summoned to meetings with parents or when children are faced with certain difficulties.

Keywords: Pedagogical Research, Family Involvement, Child Education, Involving School, Family-School Relationship

The particular complexity of the educational phenomenon, it's multidimensional and multi determined character, the infinity of the variables subsumed and the diversity of aspects of this phenomenon render research in this domain absolutely necessary.

Pedagogical research is a critical, dynamic and continuous process of knowledge, where systematic questions are formulated regarding the components and variables of the educational phenomenon, as answers to these questions are sought.

Any attempt to characterize pedagogical research should take as its starting point the object of study and research, namely the educational phenomenon, which, as already mentioned, is multidimensional and multidetermined. The nature, complexity and scale of this phenomenon lent some specific features and notes to pedagogical research, compared with research conducted in other fields of knowledge.

Pedagogical research implies sets of systematic and complex approaches, designed, designed, planned, organized, coordinated and evaluated according to an algorithmic ranking. Research design is not a mechanical process of collecting data, interpreting, processing and evaluating them, but a dynamic process characterized by the researcher's feelings of uncertainty, questions, struggles and searches for a solution to a problem, feelings which give it a problematic character.

The set of steps involved is not rigid, but flexible, supple, adaptive, making it possible to change the research methodology during its performance. Thus, the call to the researcher's creativity, to his potential to adjust to the concrete situation, his critical attitude at all stages of the research is imperatively necessary.

The researcher is faced with situations in which he is forced to conceptualize an idea, raise new questions, revise certain models of organizing the research, collect other types of data, in addition to those initially established etc. Therefore, pedagogical research is a dynamic and creative process of knowledge, which involves intuition, imagination, creativity, critical attitude and takes place within a well-established scientific investigation framework.

Pedagogic scientific research methods and procedures are part of scientific research methods and procedures, as they aim to discover new truths, in particular, to study the educational

(c) The International Journal of Indian Psychology, ISSN 2348-5396 (e)| ISSN: 2349-3429 (p) | 165 


\section{Family Involvement in Child Education and the Family-School Relationship in Romania}

phenomenon. It is appropriate to mention here that there are methods of research in the sphere of general methodology, which are used by most sciences - for example, observation and experiment (adapted to the specificity of the respective research domain) and research methods belonging to the sphere of particular methodology, characteristic of a science or group of sciences - methods such as: the method of analysing curricular and other school documents, which is characteristic of pedagogical research.

Just as with educational activities, in scientific research, the research methods and techniques are not used in isolation but integrated into sets of investigative techniques and, more specifically, methodological systems in which they interact, complement each other, are mutually supportive and act convergently.

The system of pedagogical research methods represents the set of the methods and procedures used in the scientific research of the educational phenomenon and comprise operational tools for the knowledge and deep understanding of the educational process, and for the discovery of new truths.

The pedagogical research methodology represents the theory and practice of pedagogical research methods and procedures, the science that studies the essence, nature, definition, status, classification and requirements to exploit them and build explanatory methods. Knowledge of this methodology is absolutely necessary in order to be able to apply the most effective methods and procedures to various particular cases of pedagogical research, as well as find the best methods to customize and combine them.

\section{Classification criteria for pedagogical research}

\section{According to the essence and objectives of the research}

1. Fundamental-theoretical research - which opens new perspectives upon the educational phenomenon;

2. Practical-applicative research - addressing a restricted issue and aiming to improve the explored domain - for example: assessing school performance and enriching concrete ways of action;

3. Development or operational research - aimed at implementing the results of any type of research. This is of great importance because it introduces innovations in education and constitutes the source of new hypotheses.

\section{According to the performed function}

1. Observant research - pursuing knowledge and rigorous description of certain situations;

2. Improvement research - which aim to verify the effectiveness of certain interventions; 


\section{Family Involvement in Child Education and the Family-School Relationship in Romania}

\section{According to the work methodology}

1. Observational (non-experimental) research - conclusions are more theoretical, the research is descriptive, ranging from the particular to the general;

2. Experimental research - lead to the discovery of causal relationships between educational action items. The researched phenomena are quantified and then generalized. In these types of research there is no clear-cut demarcation; they interfere and complement each other.

\section{THE STAGES OF PEDAGOGICAL RESEARCH}

Pedagogical research was designed as a systematic approach covering several stages:

1. Identifying and formulating the research question implies: seizing a research problem for which there is still no appropriate application. This problem may occur spontaneously from the observation of facts or may be raised intentionally. In any case, it should be quite restricted in order to be understood in its entirety and expressed as clearly as possible. It should not be a pseudo-problem; adequate and accurate formulation of the investigated problem, otherwise the research is at risk of wandering off the path and exhausting itself;

2. Documentation outlining objectives - is achieved simultaneously with determining (choosing) the theme and defining objectives, namely: why is research undertaken? What are the aims of the research?

3. Building the analysis model: performing the transition from theory (expressed as concepts) to the concrete reality as an object of scientific analysis within a new stage of its development; formulating the objectives and research hypotheses - the objective is formulated in a more general form by taking into account all the variables to be analysed. The hypothesis is a "provisional idea" about a fact, a social, pedagogical phenomenon, etc. specification and operationalization of variables - the factor with which the experimenter operates is the manipulated independent variable and the changes that have occurred and that are to be measured and explained constitute the dependent variable.

4. Sampling: it should meet statistical requirements of representativeness, homogeneity, sample size increased rigor.

5. Application of data collection methods and techniques: the researcher should have the competence and ability required for correct use of tools in gathering data relevant to the research conducted.

6. Processing and interpretation of data: This implies operations of analysis, synthesis, comparison, abstraction, generalization, (inductive, deductive) reasoning, and methodological competence.

The ultimate objective of the pedagogical research is to improve pedagogical action, which directly or indirectly - is related to school performance. This is also the reason for which the pedagogical investigation is exercised on some objective facts that exist outside of us. 


\section{Family Involvement in Child Education and the Family-School Relationship in Romania}

Pedagogical research is not insight, but a deep search for new ways to conduct education by scientifically explaining educational activities carried out at a given moment and - at the same time - to improve the educational process by proposing education innovation.

\section{PEDAGOGICAL RESEARCH}

\section{Identification and formulation of the research questions}

In a society where profound changes occur at a fast pace, under the circumstances of prolonged and painful transition, a representative number of the Romanian population is in a situation of dependence on the state and its institutions.

In the context of major transformations in all areas, from the economic, social, political, to the cultural and ideological, a part of the population is seeking solutions for survival or improving the family living conditions. Thus, the economic factor becomes absolutely essential to overcoming, first and foremost, material difficulties.

Determined by this reality, many parents have gone to work abroad, others have taken a second job to increase family income and a large number of them remained unemployed, on the verge of poverty.

Concerned with these issues and many others, parents have forgotten about their parental duties towards their children such as watching them and getting actively involved in their school and extracurricular activities.

Other parents have demanding jobs that take most of their day and, reaching home tired and very late, are no longer able to take care of their children. Due to lack of attention and supervision from parents, some children begin to neglect homework and school, miss classes and no longer get involved in the educational process, their school performance diminishing as a result.

School and family are the two supporting pillars of education, and between these and the extraschool or extra-family environment the child vacillates as an object and subject of education. The school-family collaboration should obviously focus on the quality of education: higher goals, ways and means.

In the current context, these links appear to be more necessary than ever. Indeed, the social mission of the school increasingly surpasses the mere achievement of the pedagogical objectives from the school curriculum, given also the fact that many parents are too concerned with family, social or professional problems in order to be able to attend to their child's progress or the consistency between the education that the child receives and the education received by the child in the family and at school. 


\section{Family Involvement in Child Education and the Family-School Relationship in Romania}

To this end, we conducted an experimental research aiming to optimize the study of concrete possibilities for improving the school-family communication and the consequences entailed by this optimization.

\section{Building the analysis model}

School-family partnerships do not produce successful students. Rather partnership activities that involve teachers, parents and students engage, guide, energize and motivate students so that they achieve success by themselves. The basic idea is that groups invest in schooling children by providing them with resources and motivational frameworks to support them in choosing successful strategies. Social exchanges through a good structure of programs may produce the human and social capital that we want as a result of school-family partnerships.

Today's everyday reality of families is different from that of previous generations. Parents and children spend far less time together and nearly all adults are faced with a constant desire to balance the demands of family life with those of their jobs. At a time when parents are under fantastic pressure that makes them less able to participate in their children's lives, there is an even greater need to get involved, especially in education.

\section{Research objectives}

1. Identifying the dimensions of families' understanding of the need for communication with the school.

2. The parents' awareness of the need to get involved in the educational process of their children.

3. Establishing a real school-family partnership to increase the children's self-confidence.

\section{Specific objectives}

1. Knowing the views of parents on child education in schools and the involvement of the school in the development of the family-school relationship.

2. Knowing students' opinions on family involvement in their education.

3. Knowing students' opinions on the school's getting the family involved in education.

4. Tracking the consistency of views expressed by parents and students on the family-school relationship.

5. Elaborating, on the basis of the findings, a concrete programme for a better family-school collaboration.

\section{The working hypotheses}

The interest of parents towards school and the education that their children receive is also manifested in the child's interest in school and his/her own education. 


\section{Family Involvement in Child Education and the Family-School Relationship in Romania}

If the school is not effective in working with the family, then the student takes advantage of the negligence of the school and how the school is appreciated differs according to it.

\section{Variables}

Dependent: family involvement in the child's education; - a closer monitoring of the child; relating the behaviour to the other children from the school group; - knowing the position of the child within the group to which he belongs.

Independent: involvement of the school in the family-school relationship; - knowledge of a child's family situation; understanding the child's needs and behaviour; efficient communication between the two parts: parents and school; - appreciation of the student's needs; - accepting and respecting the child's position towards the community or group to which he belongs; recognition of the system of rules and demands of the family to which the child belongs and based on which he/she will be further evaluated; - knowledge of the community to which the child belongs; - appreciation and evaluation from the members of the community to which he belongs.

\section{Experimental sample}

The research subjects are students in the $12^{\text {th }}$ grade, the Profile Services, the domain of Tourism and food, and their parents.

The team of this class consists of 92 students, 44 girls and 48 boys from different backgrounds, with socially and financially vulnerable, 36 of them from urban areas and the remaining 56 families from rural areas.

\section{Research data collection methods and techniques}

The method we have used in the first stage of our research was the observation of the students in the classroom in terms of their behaviour, involvement in school and extracurricular activities, how they socialize within the group of students and at school. After that, I undertook conversation with the students in the class regarding their relationship with their parents, the degree to which their parents guide and support them in school and extracurricular activities. This method was subsequently extended to parents and the teachers who teach at that class.

At the meeting with the parents from the first semester of this school year, I used the same method on students and their parents, i.e. the questionnaire-based inquiry, with questions on the family-school relationship, how they appreciate this relationship, if it actually exists and if they think that the school provides good studying conditions and gets sufficiently involved in building and maintaining a real family-school relationship. 


\section{Family Involvement in Child Education and the Family-School Relationship in Romania}

Another method used in this research was the study of documents, from which we could collect data on the knowledge gained by children from different disciplines.

Throughout the $1^{\text {st }}$ and $2^{\text {nd }}$ semester (until the next meeting with the parents) we monitored the involvement of parents in their children's school activities and extracurricular activities, we asked them to respond to certain requirements of the school and of the children, trying to get them more actively involved in school activities. At the same time, we tried to respond as best and fast as possible to the requests of parents who have shown an interest in the school and behaviour situation of their children.

There was also monitored the behaviour of children whose parents had contacted the school, inquiring into their learning performance and behaviour, in comparison with the attitudes and behaviour of students whose parents had not responded to the requests of the school or school master.

\section{Statistical processing and interpretation of the data from the questionnaire for students}

The main purpose of this questionnaire was to identify the students' opinion about the school's involvement of the family in their education and the consequences of a more aggressive involvement of parents in their children's education.

The sample group consisted of 92 students in the class for whom I am the head teacher and the students' parents, belonging to different social classes and backgrounds.

A set of questions aimed at revealing the current circumstances of family-school collaboration. The students' answers revealed that at present there is no close cooperation between parents and schools, which generates a superficial attitude towards the educational system. Over $75 \%$ of those surveyed concluded that good, efficient and regular involvement and informing of parents about their children's school situation and behaviour would diminish behavioural problems and enhance a more active involvement in the learning process.

To the question: How often are you asked by a family member about what happened at school?, the students answered: daily - 13,05\%; twice a week - 21.74\%; during the weekend - 34.78\%; once a month - 26.08\%; never - $4.35 \%$. 
Family Involvement in Child Education and the Family-School Relationship in Romania

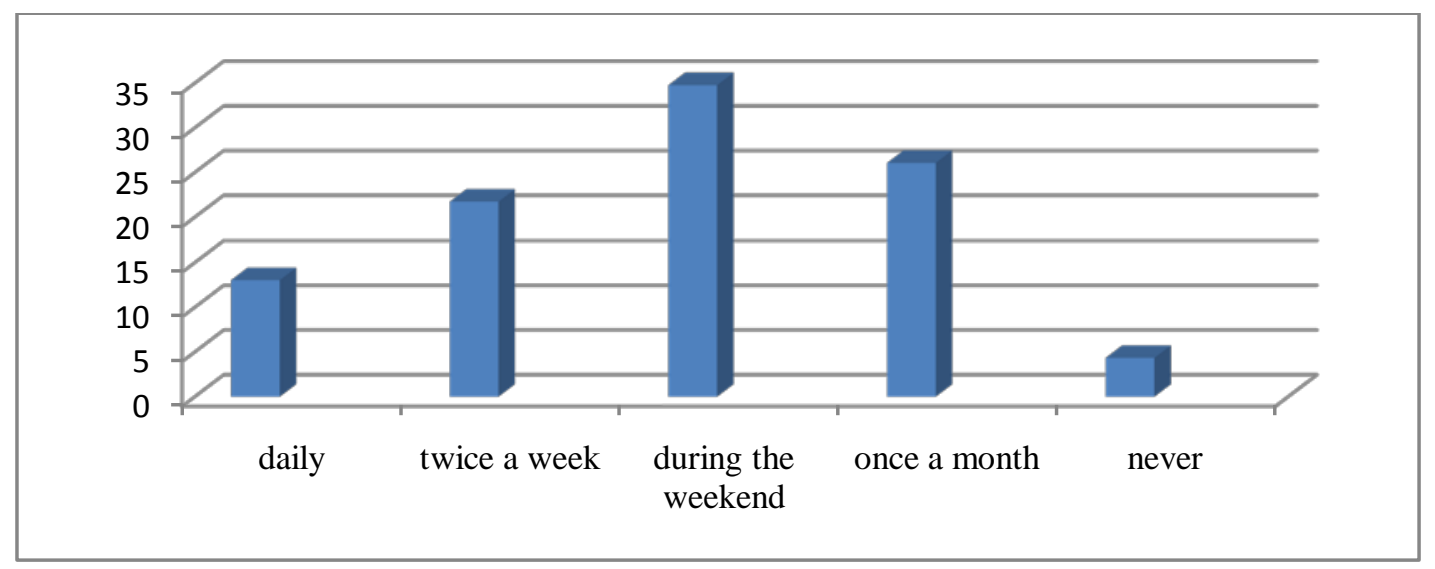

Chart 1. How often are you asked by a family member about what happened at school

As shown in these charts, family involvement in children's education is, at present, low. The reasons for the situation are various and more or less justified. The following graphs will clearly show the students' input on changing their behaviour in the case of a better collaboration between family and school.

To the question: Do you believe that school notifications to parents about your school situation would reduce the risk of certain problems?, the students answered by: "yes"- 73.92\%; "no" 21.73\%; "I do not know” - 4.35\%.

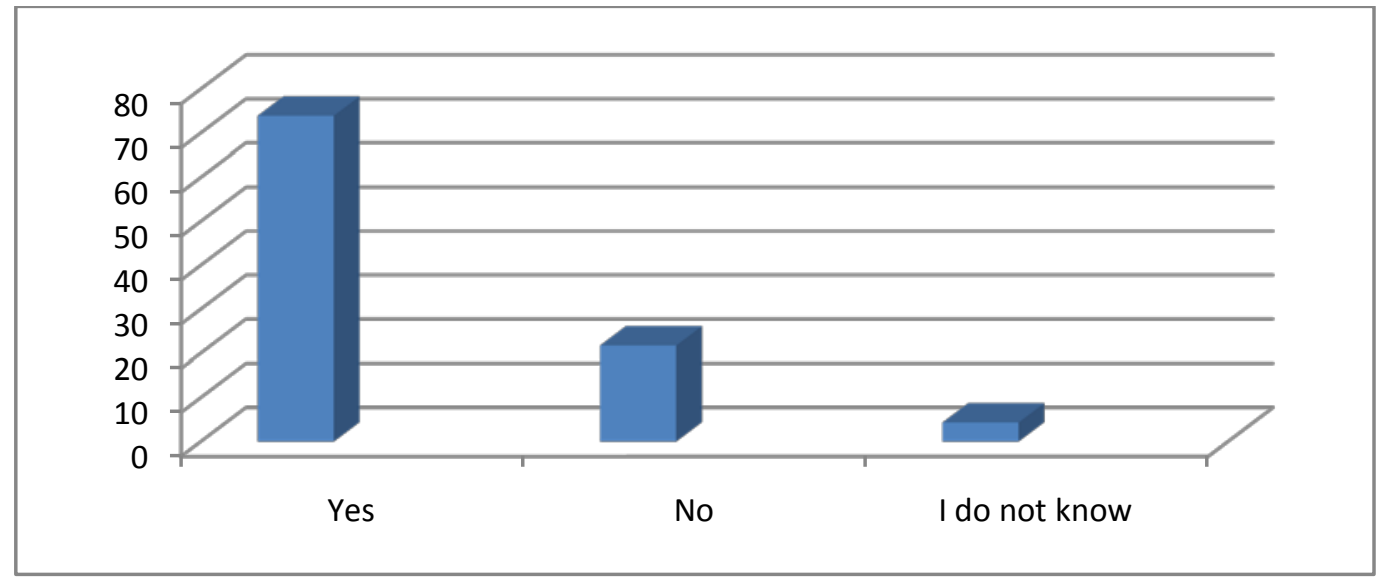

Chart 2. Do you believe that school notifications to parents about your school situation would reduce the risk of certain problems

\section{Statistical processing and interpretation of the data from the questionnaire for parents}

The main purpose of this questionnaire was to get input from parents on how their cooperation and involvement in their children's learning activities and their view of an educational partnership between family and school.

(c) The International Journal of Indian Psychology, ISSN 2348-5396 (e)| ISSN: 2349-3429 (p) | 172 
The parents' questionnaire highlights the parents' interest in school, most often when they are notified, through various methods by the head teacher, about the child's school situation or behaviour deviations.

To the question: When do you go to your child's school to inquire about his/her school situation or other situations related to him/her?, the answer options were:

a - when you're invited, b - when you have certain complaints / grievances, c - on the occasion of voluntary participation in school projects, d - daily, via the Internet, e - other, parents are asked to mention other situations.

From the parents who completed the questionnaire, $73.68 \%$ responded that they go to school when notified / invited, $21.06 \%$ of them go to the school where their children learn when they have complaints or certain grievances, and a percentage of $5.26 \%$ go to their children's school for voluntary participation in various school projects. The option to access the computer to connect with the school was not ticked by any parent. For the option "other situations", some parents revealed that they sometimes learn news about their own children from their children's classmates or the classmates’ parents.

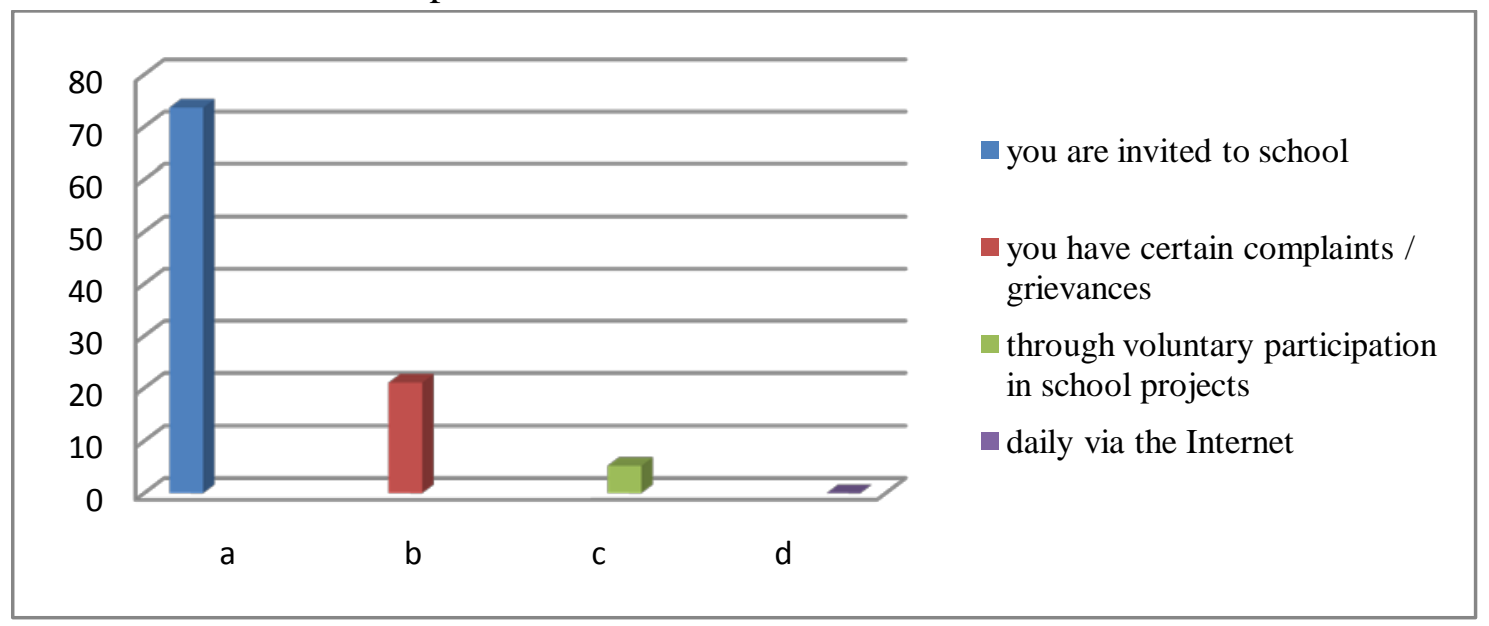

Chart 3. When do you go to your child's school to inquire about his/her school situation or other situations related to him/her

\section{DISCUSSIONS AND CONCLUSIONS}

Processing the statistical-experimental and material data highlighted an increased level of the interest of parents, and of the family in general, towards school and the needs of their own children, revealing a bond that should constantly exist between these two institutions: family and school.

As children experience a greater involvement of the family in their school and extracurricular activities, the existence of a connection between families and schools, they give more importance to the educational process and school attendance.

(C) The International Journal of Indian Psychology, ISSN 2348-5396 (e) | ISSN: 2349-3429 (p) | 173 


\section{Family Involvement in Child Education and the Family-School Relationship in Romania}

If at the meeting from the $1^{\text {st }}$ semester parents did not show much interest in school and the educational act of their children, during the $2^{\text {nd }}$ semester there was an increase in the degree of their involvement in school life, in the formative training of their children and the school activities organized for the benefit of the school and students.

An important role in building and developing a genuine connection between family and school was played by the strategies and methods used by the head of school, the teaching staff and myself, as a head teacher, to attract and engage families in shared activities, ask for support in the development and implementation of educational projects, find volunteers for activities conducted with the students at class or school level.

Based on the fact that during the school year, from the first meeting with the parents and until the present moment I have managed to build and develop a partnership relationship between the parents of the students in my class and the school, represented by the unit management, teachers and myself as head teacher of the respective class, I believe that the strategies (methods and techniques) used were effective and gave the expected result. This relationship should be further maintained and developed in order to achieve the results that we want in our work as educators.

During this research we came across positive attitudes from subjects, such as: commitment, adaptation, acceptance, satisfaction, understanding, conformism, but there were also negative attitudes, such as: insubordination, absenteeism, rejection, antipathy, non-communication, isolation.

The conclusion we should draw is that cooperation between school and family means an agreement where each partner should respond to the other's needs and intentions. In order for this to be possible, parents should contact the school not only when they are summoned to meetings with parents or when children are faced with certain difficulties.

Parents should attend all the school's important events that involve their children (festivities, contests, performances, celebrations, etc.), support the school at least by their vote of trust if not also materially, facilitate the school's educational mission by continuing education at home, show willingness to participate in educational courses conducted by the school for parents, etc.

Involving parents in the school education of children relies on several principles, the breaching of which renders this relationship flawed and ineffective. Here are some of these principles: parents want the best for their children; - regardless of ethnicity, socioeconomic status or educational training, parents are a key element in the education of their children; - all children are able to learn; - the main element is the child and his/her successes; - the school is not the only one responsible for the child's school performance; - every teacher is a specialist in his/her domain, providing children with information that is relevant and age appropriate; - together as

(c) The International Journal of Indian Psychology, ISSN 2348-5396 (e)| ISSN: 2349-3429 (p) | 174 


\section{Family Involvement in Child Education and the Family-School Relationship in Romania}

partners: the school, family and community may succeed in educating children for a happy, healthy and productive life. As partners in a relationship, it is natural that both school and family should have certain mutual demands.

Teachers expect of parents to: - be involved in all the aspects of their children's life (provide them with favourable physical and mental development conditions); - create learning opportunities for their children (ensure a safe, peaceful environment that fosters learning); highlight, in their discussions with children, the importance of life-long learning; - support students to achieve balance between school and extra-school activities; - support the school's goals, rules and policy; - communicate often and openly with teachers (without offending or criticising the latter's professional competence); - teach their children self-discipline and respect towards others; - teach their children how to say "no" to the pressures of their entourage;

Accept their responsibilities of parent by being a good example; - last but not least, encourage their children to be the best and set realistic goals.

Parents, too, have certain expectations of teachers regarding the teaching activity, namely: - to support children in enhancing their self-esteem; - to be sensitive to the special needs, interests and talents of children; - to communicate often and openly with parents; - to set identical school tasks for all students; - to show enthusiasm in educating children; - to treat all children equally; to consolidate the children's positive discipline; - to provide information on how parents may help their children learn.

\section{Acknowledgments}

The author appreciates all those who participated in the study and helped to facilitate the research process.

Conflict of Interests: The author declared no conflict of interests.

\section{REFERENCES}

Antonesei, L, (2009), Guide to research education, Publisher Polirom, Iasi.

Cazacu, A, Badescu, I, (1981), Methods and techniques of sociological research, Guide applicative, Part I, University of Bucharest.

Dumitriu, C, (2011), Pedagogical research methodology, Publisher Alma Mater, Bacau.

Dumitriu, Gh, (1998), Communication and learning, Didactic and Pedagogical R.A., Bucharest. Iluţ, P, (1997). Sociohuman qualitative approach, Publisher Polirom, Iasi.

Lupu, C, (2013), Epistemological and Psychological Fundamentals of the Didactics of Science, Social and Behavioral Sciences, Volume: 92, Pages: 490-494, UK, http://www.sciencedirect.com/science/article/pii/S1877042813028371

(C) The International Journal of Indian Psychology, ISSN 2348-5396 (e) | ISSN: 2349-3429 (p) | 175 


\section{Family Involvement in Child Education and the Family-School Relationship in Romania}

Lupu, C, (2014), Research on the Individual Development of Children by eliminating stressors, The International Journal of Indian Psychology, Volume 2, Issue 1, October to December 2014, Pages 102-114, http://www.ijip

Lupu, C, (2014), The analytical-synthetic presentation of the psycho-Pedagogical paradigm of discipline didactics, Social and Behavioral Sciences, Volume: 149, Pages: 508-512, UK, http://www.sciencedirect.com/science/article/pii/S1877042814050125

Lupu, C, (2014), The Psycho-Pedagogical Paradigm of Didactics courses, LAMBERT Academic Publishing Co. OmniScriptum GmbHet KG, Saarbrücken, Deutschland / Germany,

Lupu, C, (2015), Creativity and pedagogical research, Publisher Alma Mater, Bacau.

Lupu, C, (2015), Empirical Research Concerning the Elimination of Violence in Mathematics Lessons, The International Journal of Indian Psychology, Volume 2, Issue 2, January to March 2015, Pages. 138-150, http://www.ijip

Rateau, P, (2004), Experimental methods and statistics in the humanities, Publisher Polirom, Iaşi.

How to cite this article: Lupu C (2017), Family Involvement in Child Education and the Family-School Relationship in Romania, International Journal of Indian Psychology, Volume 4, Issue 2, No. 94, ISSN:2348-5396 (e), ISSN:2349-3429 (p), DIP:18.01.157/20170402, ISBN:9781-365-84229-0 